\title{
Induction of Labor Using One Dose versus Multiple Doses of Misoprostol: RCT
}

\author{
HISHAM M.M. HARB, M.D.*; DINA Y. MANSOUR, M.D.* and NAHED Sh. MOHAMMED, M.Sc.** \\ The Department of Obstetrics and Gynecology, Faculty of Medicine, Ain Shams University* and Aswan Insurance Hospital**
}

\begin{abstract}
Background: Situations arise in obstetrics where it becomes necessary to end a pregnancy in the interest of the mother or baby or both. There is a growing interest in the use of misoprostol, a prostaglandin E1 analogue for labour induction. Induction of labour is a common obstetric intervention and the use of misoprostol as an induction agent is important due to its low cost and stability at room temperature. These additional advantages make it a suitable agent, particularly in under-resourced settings and tropical countries.
\end{abstract}

Aim of Study: This study was conducted to compare the rate of vaginal delivery within 24 hour among patients who undergo induction of labor between those who receive vaginal single dose of misoprostol with those receive up to 5 doses of this medication.

Patients and Methods: The study was a randomized controlled open labeled clinical trial, study setting was $\mathrm{Ob}$ stetrics and Gynecology Department of Ain Shams Maternity University Hospital (Emergency Department), the study timing was 6 months from March to September 2019, this study was conducted on 206 women who came to Emergency Department of Obstetrics and Gynecology Department of Ain Shams Maternity University Hospital.

Results: The majority (70.87\%) had V D in 24 hours in one dose group versus $75.73 \%$ in multiple doses without significant difference between both groups. Time from induction to delivery in one dose group ranged from 10-32 with mean value of $17.990 \pm 5.579$ while in multi-dose group was 10 -33 (with mean value $18.204 \pm 5.206$ ) without significant difference between groups. Latent period in one dose group ranged from 3-11 with mean value of $5.918 \pm 2.077$ while in multi-dose group was 3-12 (with mean value $6.500 \pm 2.173$ ) without significant difference between groups. There was non-significant difference between one dose and multiple doses in incidence of fetal distress as the majority in one dose group $92.23 \%$ than $90.29 \%$ in muti-dose group.

Conclusion: The single-dose misoprostol appears to be an acceptable alternative to a multiple dose regimen for cervical ripening before the induction of labor. Our data indicates that there was no difference regarding the clinical

Correspondence to: Dr. Hisham M.M. Harb, The Department of Obstetrics and Gynecology, Faculty of Medicine, Ain Shams University efficacy between two labour induction regimens of vaginal misoprostol.

Key Words: Labor-Multiple doses - Misoprostol-RCT.

\section{Introduction}

LABOR induction is an intervention that artificially initiates uterine contractions leading to progressive dilatation and effacement of the cervix and birth of the baby, and is to be considered when the risks of continuing pregnancy are outweighed the risks of terminating it. Labor induction is a procedure used for a broad range of common conditions: Post-term pregnancy, pregnancy induced hypertension, pre-eclampsia, eclampsia, maternal diabetes, premature rupture of membranes, intrauterine fetal growth restriction, chorioamnionitis, fetal death, A prompt delivery reduces maternal or neonatal morbidity and mortality [1]

Methods of preparing uterine cervix and inducing labor include administration of oxytocin, prostaglandins, prostaglandin analogues, mifepristone, or mechanical procedures (amniotomy, intracervical Foley catheter, and sweeping of the membranes). There is a great concern about their effectiveness and safety [2].

Misoprostol is a synthetic analogue of prostaglandin E1 with a plasma half-life of $<1$ hour when given vaginally [3]. The dose mostly recommended is 25 or 50 misoprostol vaginally. However, there are few studies that address the repeat dosing and frequency of dosing of misoprostol. Although 3 hours might be the most appropriate interval based on the half-life, it is not known how well serum level correlates with clinical effect. Also, it is unknown whether repeat doses result in a cumulative effect or whether there is a latency period between the application of the drug and biochemical 
changes in the cervix. One study suggested a single dose is most effective if it is given 12 hours before oxytocin is initiated [4].

Repeat dosing may extend the latent phase of labor. A longer latent phase of labor is associated with an increased rate of cesarean delivery, chorioamnionitis, endometritis, and uterine atony [5].

A previous study hypothesized that repeating the dose of misoprostol extends the cervical ripening time and thus decreases the proportion of women who deliver vaginally within 24 hour after the administration of the first dose of misoprostol. Therefore they compared the rate of vaginal delivery within 24 hour among patients who undergo induction of labor between those who receive a single dose of misoprostol with those receive multiple doses and they found that $50 \%$ of women in the multiple dose group would deliver vaginally in 24 hours. A sample size of 220 patients was needed to detect a $20 \%$ increase in vaginal delivery rate within 24 hours in the 1 dose misoprostol group [6].

\section{Aim of the work:}

This study was conducted to compare the rate of vaginal delivery within 24 hour among patients who undergo induction of labor between those who receive a single dose of misoprostol with those receive up to 5 doses of this medication.

\section{Patients and Methods}

Type of study: Randomized controlled open labeled clinical trial.

Study setting: Obstetrics and Gynecology Department of Ain Shams Maternity University Hospital (Emergency Department).

Study timing: 6 months from March to September 2019.

Randomization: Was done using computer generated randomization sheet using Medcalc version 13.

Allocation and concealment: 206 opaque envelopes were numbered serially and in each envelope, the corresponding letter which denotes the allocated group was put according to randomization table. Then all envelopes were closed and put in one box. When each patient arrived, a random envelope was opened and the patient was allocated according to the mode of induction written in the envelope.

Study population: This study was conducted on 206 women who came to Emergency Depart- ment of Obstetrics and Gynecology Department of Ain Shams Maternity University Hospital.

\section{Inclusion criteria:}

1- Primigravid women.

2- Age: 20-35.

3- Singleton term pregnancies (40-42 weeks of gestation).

4- Normal laboratory investigations.

5- AFI: $10-20 \mathrm{~cm}$.

6- Normal placental location.

7- Estimated fetal weight $(2.5-3.5 \mathrm{~kg})$.

8- Fetal monitoring was category I by CTG.

\section{Exclusion criteria:}

1- Previous C.S.

2- Contraindication to misoprostol.

3- Contraindication to vaginal delivery.

4- Fetal death, major fetal anomaly, or fetal growth restriction.

5- Premature rupture of membranes.

6- Associated medical conditions like D.M, HTN, PET.

\section{- Sample size:}

Group 1: Include 103 women who received $25 \mu \mathrm{g}$ of misoprostol as a single dose Vaginally (Vagiprost).

Group 2: Include 103 women who received up to 5 doses of misoprostol starting with $25 \mu \mathrm{g}$ in the form of one tablet of vagiprost vaginally repeated every 6 hours.

\section{- Process of delivery:}

In the multiple dose misoprostol group, misoprostol $25 \mu \mathrm{g}$ (vagiprost $25 \mu \mathrm{g}$ ) was administered vaginally every 4-6 hours for a maximum of 5 doses. Before insertion of each repeated dose, the patient condition was evaluated. If the patient had regular efficient uterine contractions, or fetal monitoring wasn't category I, no further misoprostol would be given. Alert and action lines were drawn when the women was in the active phase of labour.

- Maternal assessment included (BP, pulse, Temperature).

- Fetal assessment included (amniotic fluid color and volume monitoring and fetal heart rate monitoring). 
- Vaginal examination was performed 4 hours after the initial one or earlier if showed dilatation between Alert and action line, subsequent examination was carried out in 2 hours.

- If there were no cervical changes, no contractions in both groups within 24 hour of first dose, failed induction was considered.

- If there were fetal complications (fetal monitoring wasn't category I), maternal complications or failed induction, cesarean section was considered.

\section{Study procedure:}

All the patients were subjected to the following:

- Informed consent was taken:

1- Complete history was taken.

2- General examination.

3- Abdominal examination.

4- Abdominal ultrasound.

5- Investigations: $\mathrm{CBC}$, urine analysis for albumin and sugar, blood group, RH type.

6- CTG.

\section{Results}

Table (1): V D in 24 hours.

\begin{tabular}{|c|c|c|c|c|c|c|c|c|}
\hline \multirow{3}{*}{$\begin{array}{l}V D \text { in } \\
24 \text { hours }\end{array}$} & \multicolumn{6}{|c|}{ Groups } & \multirow{2}{*}{\multicolumn{2}{|c|}{ Chi-square }} \\
\hline & \multicolumn{2}{|c|}{ Ond dose } & \multicolumn{2}{|c|}{ Multi-dose } & \multicolumn{2}{|r|}{ Total } & & \\
\hline & $\mathrm{N}$ & $\%$ & $\mathrm{~N}$ & $\%$ & $\mathrm{~N}$ & $\%$ & $x^{2}$ & $p$-value \\
\hline No & 30 & 29.13 & 25 & 24.27 & 55 & 26.70 & 0.620 & 0.431 \\
\hline Yes & 73 & 70.87 & 78 & 75.73 & 151 & 73.30 & & \\
\hline Total & 103 & 100.00 & 103 & 100.00 & 206 & 100.00 & & \\
\hline
\end{tabular}

The majority (70.87\%) had V D in 24 hours in one dose group versus $75.73 \%$ in multiple doses without significant difference between both groups $(p=0.431)$.

Table (2): Incidence of neonatal morbidities.

\begin{tabular}{|c|c|c|c|c|c|c|c|c|}
\hline \multirow{3}{*}{$\begin{array}{l}\text { Neonatal } \\
\text { morbidities }\end{array}$} & \multicolumn{6}{|c|}{ Groups } & \multirow{2}{*}{\multicolumn{2}{|c|}{$\begin{array}{l}\text { Chi- } \\
\text { square }\end{array}$}} \\
\hline & \multicolumn{2}{|c|}{ Ond dose } & \multicolumn{2}{|c|}{ Multi-dose } & \multicolumn{2}{|c|}{ Total } & & \\
\hline & $\mathrm{N}$ & $\%$ & $\mathrm{~N}$ & $\%$ & $\mathbf{N}$ & $\%$ & $x^{2}$ & $\begin{array}{c}p- \\
\text { value }\end{array}$ \\
\hline - No & 70 & 67.96 & 83 & 80.58 & 153 & 74.27 & 5.247 & 0.155 \\
\hline $\begin{array}{l}\text { - Supplemental } \\
\text { oxygen }\end{array}$ & 18 & 17.48 & 9 & 8.74 & 27 & 13.11 & & \\
\hline $\begin{array}{l}\text { • NICU } \\
\text { admission }\end{array}$ & 6 & 5.83 & 6 & 5.83 & 12 & 5.83 & & \\
\hline $\begin{array}{l}\text { - Low APGAR } \\
\text { score }\end{array}$ & 9 & 8.74 & 5 & 4.85 & 14 & 6.80 & & \\
\hline Total & 103 & 100.00 & 103 & 100.00 & 206 & 100.00 & & \\
\hline
\end{tabular}

The majority $(67.96 \%)$ of cases in one dose group had no neonatal morbidities versus $80.58 \%$ in mult-idose group while supplemental oxygen, NICU admission and low APGAR score was $17.48 \%, 5.83 \%$ and $8.74 \%$ respectively in single dose group versus $8.74 \%, 5.83 \%$ and $4.85 \%$ respectively in muted dose group without significant difference between both groups ( $p=0.155)$.

Table (3): Time from induction to delivery (hours).

\begin{tabular}{llllll}
\hline \multirow{2}{*}{$\begin{array}{l}\text { Time from induction } \\
\text { to delivery (hours) }\end{array}$} & \multicolumn{2}{c}{ Groups } & & \multicolumn{2}{c}{$t$-test } \\
\cline { 2 - 3 } \cline { 5 - 6 } & Ond dose & Multi-dose & & $t$ & $p$-value \\
\hline Range & $10-32$ & $10-33$ & -0.284 & 0.777 \\
Mean \pm SD & $17.990 \pm 5.579$ & $10.204 \pm 5.206$ & & \\
\hline
\end{tabular}

Time from induction to delivery in one dose group ranged from 10-32 with mean value of 17.990 \pm 5.579 while $\mathrm{n}$ multi-dose group was $10-33$ (with mean value $18.204 \pm 5.206$ ) without significant difference between groups as $p=0.777$.

Table (4): Latent period (hours).

\begin{tabular}{lllll}
\hline \multirow{2}{*}{$\begin{array}{l}\text { Latent period } \\
\text { (hours) }\end{array}$} & \multicolumn{2}{c}{ Groups } & \multicolumn{2}{c}{$t$-test } \\
\cline { 2 - 5 } & Ond dose & Multi-dose & $t$ & $p$-value \\
\hline Range & $3-11$ & $3-12$ & -1.791 & 0.075 \\
Mean \pm SD & $5.918 \pm 2.077$ & $6.500 \pm 2.173$ & & \\
\hline
\end{tabular}

Latent period in one dose group ranged from $3-11$ with mean value of $5.918 \pm 2.077$ while in multi-dose group was 3-12 (with mean value $6.500 \pm$ 2.173) without significant difference between groups as $p=0.075$.

Table (5): Latent period (hours).

\begin{tabular}{|c|c|c|c|c|c|c|c|c|}
\hline \multirow{3}{*}{$\begin{array}{l}\text { Indication } \\
\text { of C.S }\end{array}$} & \multicolumn{6}{|c|}{ Groups } & \multirow{2}{*}{\multicolumn{2}{|c|}{$\begin{array}{l}\text { Chi- } \\
\text { square }\end{array}$}} \\
\hline & \multicolumn{2}{|c|}{ Ond dose } & \multicolumn{2}{|c|}{ Multi-dose } & \multicolumn{2}{|c|}{ Total } & & \\
\hline & $\mathrm{N}$ & $\%$ & $\mathrm{~N}$ & $\%$ & $\mathrm{~N}$ & $\%$ & $x^{2}$ & $\begin{array}{c}p- \\
\text { value }\end{array}$ \\
\hline - Failed Induction & 18 & 60.00 & 17 & 68.00 & 35 & 63.64 & 0.377 & 0.828 \\
\hline $\begin{array}{l}\text { - Non reassuring } \\
\text { NST }\end{array}$ & 6 & 20.00 & 4 & 16.00 & 10 & 18.18 & & \\
\hline - Obstructed labour & 6 & 10.00 & 4 & 16.00 & 10 & 18.18 & & \\
\hline Total & 30 & 100.00 & 25 & 100.00 & 55 & 100.00 & & \\
\hline
\end{tabular}

The majority (60\%) of cases in one dose group delivered by CS due to failed induction while $20 \%$ due to either non reassuring NST or obstructed labour. And in muti-dose group, the majority $(63.64 \%)$ of cases in mult-idose group delivered by CS due to failed induction while $18.18 \%$ due to either non reassuring NST or obstructed labour without significant difference between both groups $(p=0.828)$. 
Table (6): Fetal complications.

\begin{tabular}{|c|c|c|c|c|c|c|c|c|}
\hline \multirow{3}{*}{$\begin{array}{l}\text { Fetal } \\
\text { complications }\end{array}$} & \multicolumn{6}{|c|}{ Groups } & \multirow{2}{*}{\multicolumn{2}{|c|}{$\begin{array}{l}\text { Chi- } \\
\text { square }\end{array}$}} \\
\hline & \multicolumn{2}{|c|}{ Ond dose } & \multicolumn{2}{|c|}{ Multi-dose } & \multicolumn{2}{|c|}{ Total } & & \\
\hline & $\mathrm{N}$ & $\%$ & $\mathrm{~N}$ & $\%$ & $\mathrm{~N}$ & $\%$ & $x^{2}$ & $\begin{array}{c}p- \\
\text { value }\end{array}$ \\
\hline No & 95 & 92.23 & 93 & 90.29 & 188 & 91.26 & 0.243 & 0.622 \\
\hline Fetal distress & 8 & 7.77 & 10 & 9.71 & 18 & 8.74 & & \\
\hline Total & 103 & 100.00 & 103 & 100.00 & 206 & 100.00 & & \\
\hline
\end{tabular}

There was non-significant difference between one dose and multiple doses in incidence of fetal distress $(p=0.622)$ as the majority in one dose group $92.23 \%$ and $90.29 \%$ in multi dose group had no fetal distress.

Table (7): Maternal complications.

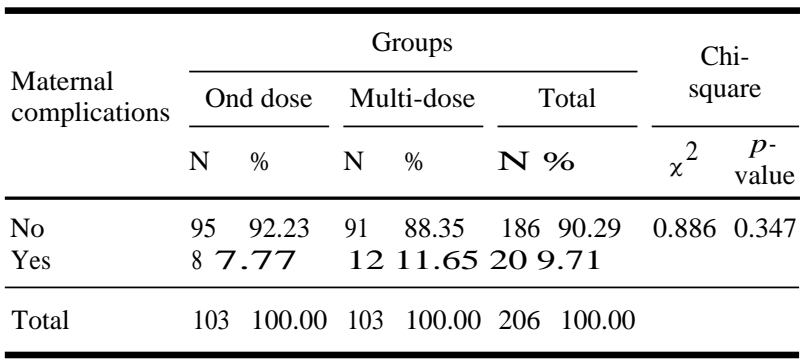

The majority (92.23\% and $88.35 \%)$ in one dose and multiple doses had no maternal complications without significant difference between both groups in the incidence of maternal complication $(p=$ 0.347).

Table (8): Maternal complications.

\begin{tabular}{|c|c|c|c|c|c|c|c|c|}
\hline \multirow{3}{*}{$\begin{array}{l}\text { Maternal } \\
\text { complications }\end{array}$} & \multicolumn{6}{|c|}{ Groups } & \multirow{2}{*}{\multicolumn{2}{|c|}{$\begin{array}{l}\text { Chi- } \\
\text { square }\end{array}$}} \\
\hline & \multicolumn{2}{|c|}{ Ond dose } & \multicolumn{2}{|c|}{ Multi-dose } & \multicolumn{2}{|c|}{ Total } & & \\
\hline & $\mathrm{N}$ & $\%$ & $\mathrm{~N}$ & $\%$ & $\mathrm{~N}$ & $\%$ & $x^{2}$ & $\begin{array}{c}p- \\
\text { value }\end{array}$ \\
\hline • No & 95 & 92.23 & 91 & 88.35 & 186 & 90.29 & 6.419 & 0.492 \\
\hline - Hyperthermia & 4 & 3.88 & 4 & 3.88 & 8 & 3.88 & & \\
\hline - Nausea & 1 & 0.97 & 0 & 0.00 & 1 & 0.49 & & \\
\hline $\begin{array}{l}\text { - Postpartum- } \\
\text { hemorrage }\end{array}$ & 1 & 0.97 & 3 & 2.91 & 4 & 1.94 & & \\
\hline - Vomiting & 1 & 0.97 & 0 & 0.00 & 1 & 0.49 & & \\
\hline - Shivering & 1 & 0.97 & 2 & 1.94 & 3 & 1.46 & & \\
\hline - Exhaustion & 0 & 0.00 & 2 & 1.94 & 2 & 0.97 & & \\
\hline - Hypersystole & 0 & 0.00 & 1 & 0.97 & 1 & 0.49 & & \\
\hline Total & 103 & 100.00 & 103 & 100.00 & 206 & 100.00 & & \\
\hline
\end{tabular}

There was non-significant difference between one dose and multiple doses in incidence of Hyperthermia, nausea, post-partum hemorrage, vomiting, shivering, exhaustion and hypersystole as $p=0.492$.

Age in one dose group ranged from 20-30 with mean value of $24.184 \pm 3.386$ while $n$ multi-dose group was 20-30 (with mean value $24.738 \pm 3.290$ ) without significant difference between groups as $p=0.236$. Weight in one dose group ranged from $65-90$ with mean value of $75.835 \pm 6.691$ while $n$ multi-dose group was 64-90 (with mean value $75.718 \pm 6.450$ ) without significant difference between groups as $p=0.899$. Height in one dose group ranged from 157-170with mean value of 162.777 \pm 3.958 while $\mathrm{n}$ multi-dose group was $157-170$ (with mean value $162.398 \pm 3.989$ ) without significant difference between groups as $p=495 \mathrm{BMI}$ in one dose group ranged from 23.88-35.16 with mean value of $28.657 \pm 2.738$ while $\mathrm{n}$ multi-dose group was 23.03-35.25 (with mean value $28.778 \pm 2.986$ ) without significant difference between groups as $p=0.762$. GA in one dose group ranged from 40 42 with mean value of $40.534 \pm 0.639$ while $n$ multidose group was 40-42 (with mean value $40.398 \pm$ 0.566 ) without significant difference between groups as $p=0.108$. Bishop score in one dose group ranged from 3-5 with mean value of $3.932 \pm 0.675$ while $\mathrm{n}$ multi-dose group was 3-5 (with mean value $3.835 \pm 0.658$ ) without significant difference between groups as $p=0.297$.

Table (9): Demographic data of both groups.

\begin{tabular}{lllll}
\hline & \multicolumn{2}{c}{ Groups } & \multicolumn{2}{c}{$t$-test } \\
\cline { 2 - 5 } & Ond dose & Multi-dose & $t$ & $p$-value \\
\hline Age: & & & & \\
$\quad$ Range & $20-30$ & $20-30$ & -1.190 & 0.236 \\
$\quad$ Mean \pm SD & $24.184 \pm 3.386$ & $24.738 \pm 3.290$ & & \\
Weight: & & & & \\
$\quad$ Range & $65-90$ & $64-90$ & 0.127 & 0.899 \\
$\quad$ Mean \pm SD & $75.835 \pm 6.691$ & $75.718 \pm 6.450$ & & \\
Height: & & & & \\
$\quad$ Range & $157-170$ & $157-170$ & 0.684 & 0.495 \\
$\quad$ Mean \pm SD & $162.777 \pm 3.958$ & $162.398 \pm 3.989$ & & \\
BMI: & & & & \\
$\quad$ Range & $23.88-35.16$ & $23.03-35.25$ & -0.304 & 0.762 \\
$\quad$ Mean \pm SD & $28.657 \pm 2.738$ & $28.778 \pm 2.986$ & & \\
GA: & & & & \\
$\quad$ Range & $40-42$ & $40-42$ & 1.616 & 0.108 \\
$\quad$ Mean \pm SD & $40.534 \pm 0.639$ & $40.398 \pm 0.566$ & & \\
Bishop score: & & & & \\
$\quad$ Range & $3-5$ & $3-5$ & 1.045 & 0.297 \\
$\quad$ Mean \pm SD & $3.932 \pm 0.675$ & $3.835 \pm 0.658$ & & \\
\hline
\end{tabular}

\section{Discussion}

We conducted this randomized control study to compare the rate of vaginal delivery within 24 hours among patients who undergo induction of labor between those who receive a single dose of misoprostol (group I) and those who receive up to 5 doses of this medication (group II).

Primary outcome was rate of vaginal delivery within 24 hour while secondary outcome including time from induction to delivery, duration of latent 
period, maternal complications (maternal exhaustion, fever, rigors, diarrhea), fetal complications (fetal distress-intra uterine fetal death), neonatal morbidities (low APGAR score-NICU admission).

In the current study, no significant difference between groups in age as $p=0.236$, weight as $p=$ 0.899 , height as $p=0.495$ and BMI as $p=0.762$ as Body Mass Index (BMI) is an important maternal characteristic that can influence the dose response to vaginal misoprostol. Obese women might be expected to require higher doses or more frequent applications, while women with a low BMI may require lower doses.

This was supported by finding of Pimentel et al., on 243 participants. There was no difference in the demographic and clinical characteristics of both treatment groups including body mass index, race/ethnicity and parity [6].

In the current study, GA in one dose group ranged from 40-42 with mean value of 40.534 \pm 0.639 while $n$ multi-dose group was 40-42 (with mean value $40.398 \pm 0.566$ ) without significant difference between groups as $p=0.108$.

In contrast, among one hundred and four women were randomized to either a single dose of 50 of intravaginal misoprostol in $24 \mathrm{~h}$, or two consecutive doses of intravaginal 50 nisoprostol $6 \mathrm{~h}$ apart included in study by Lokugamage et al., the only significant difference when comparing the maternal demographic data was mean length of gestation [7].

In the current study, Bishop score in one dose group ranged from 3-5 with mean value of 3.932 \pm 0.675 while $\mathrm{n}$ multi-dose group was 3-5 (with mean value $3.835 \pm 0.658$ ) without significant difference between groups as $p=0.297$.

And in harmony with this study's results, Lokugamage found there was no difference in the mean Bishops score between the groups [7]

Also, among five hundred twenty-two patients with indications for induction of labor and unfavorable cervices were randomly assigned by Wing and Paul, to one or two dosing regimens of vaginaly administered misoprostol. The median Bishop score obtained after administration of the initial dose of medication was 3 in both groups also not significantly different $(p>0.05)[8]$.

In the current study, the majority $(70.87 \%)$ had V D in 24 hours in one dose group versus $75.73 \%$ in multiple doses without significant difference between both groups $(p=0.431)$.
The current study's results are in harmony with Girija and Manjunath, in the 25 goup, the vaginal delivery rate with one dose was $34 \%$, two doses $28 \%$ and three doses $6 \%$. There was no significant difference between groups $(p=0.3)$ [9]

In the current study, time from induction to delivery in one dose group ranged from 10-32 hours with mean value of $17.990 \pm 5.579$ while in multi-dose group was 10-33 hours (with mean value $18.204 \pm 5.206$ ) without significant difference between groups as $p=0.777$.

This was in harmony with Pimentel et al., study showed that, the time to vaginal delivery was 1187 minutes for the 1-misoprostol group and 1321 minutes for the multiple misoprostol group ( $p=.202)$ [6]

Lokugamage et al., studied the efficacy of a single versus two dose regimen of 50 vinal misoprostol for labour induction. Although the author concluded that the two dose regimen was more effective [7].

In contrast, according to a study by Lokugamage et al., the induction to delivery interval was significantly longer in the single-dose regimen. Although this study was randomized, the results revealed heterogeneity within the maternal demographic and 'reasons for induction' data. There were more postdate pregnancies in the two-dose arm. The other component of heterogeneity that should be discussed is the greater number of suspected largefor-date fetuses in the single-dose group, although there were no eventual differences in birth weight between the groups [7].

In the current study, latent period in one dose group ranged from 3-11 with mean value of 5.918 \pm 2.077 while in multi-dose group was 3-12 (with mean value $6.500 \pm 2.173$ ) without significant difference between groups as $p=0.075$.

This goes in line with Pimentel et al., showed that, the time lapsed from the last dose of misoprostol to the initiation of oxytocin were similar for both groups [6].

In the current study, the majority $(60 \%)$ of cases in one dose group delivered by CS due to failed induction while $20 \%$ due to either non reassuring NST or obstructed labour. And in muti-dose group, The majority (63.64\%) of cases in multi-dose group delivered by CS due to failed induction while $18.18 \%$ due to either non reassuring NST or Obstructed labour without significant difference between both groups $(p=0.828)$. 
Although this results was a contrary to a study conducted by Pimentel et al., which showed that, cesarean delivery rate was greater in the 1misoprostol group compared with the multiplemisoprostol group ( $p=.034 ; 35.8 \%$ vs. $22.8 \%$ ). But its results were similar to the finding regarding there were no significant differences in the indication for cesarean delivery between groups [6]

Also, in line with current results, indications for caesarean section were comparable among groups (one dose, two doses and three doses) as reported by Girija and Manjunath [9].

In the current study, there was non-significant difference between one dose and multiple doses in incidence of fetal distress $(p=0.622)$ as the majority in one dose group $92.23 \%$ and $90.29 \%$ in multi dose group had no fetal distress. The majority $(67.96 \%)$ of cases in one dose group had no neonatal morbidities versus $80.58 \%$ in multidose group while supplemental oxygen, NICU admission and low APGAR score was $17.48 \%$, $5.83 \%$ and $8.74 \%$ respectively in single dose group versus $8.74 \%, 5.83 \%$ and $4.85 \%$ respectively in multi dose group without significant difference between both groups ( $p=0.155)$.

Similarly, Pimentel et al., showed that there were no statistically significant differences in the secondary fetal outcomes between the 2 groups. There were no cases of hypoxic-ischemic encephalopathy, intraventricular hemorrhage grade 3 or 4 , severe respiratory distress syndrome, necrotizing enterocolitis, or death [6].

Also, the neonatal outcomes were comparable among groups according to Girija and Manjunath [9].

Conflicting results was reported by Lokugamage et al., studied the efficacy of a single versus two dose regimen of $50 \mu \mathrm{g}$ vaginal misoprostol for labour induction. When evaluating aspects of intrapartum fetal well being, there was an increased amount of clinician input related to suspicious Cardiotocography (CTG) and an increased amount of intervention in the one-dose group, which approached significance. However there were no other differences detected with other parameters of intrapartum well-being [7] .

In the current study, the majority $(92.23 \%$ and $88.35 \%$ ) in one dose and multiple doses respectively had no maternal complications without significant difference between both groups $(p=0.347)$. There was non-significant difference between one dose and multiple doses in incidence of hyperther- mia, nausea, post-partum hemorrage, vomiting, shivering, exhaustion and hypersystole as $p=0.492$.

Similarly, Pimentel et al., showed that there were no statistically significant differences in the secondary maternal outcomes between the 2 groups. There was 1 case of intensive care unit admission (in the 1-misoprostol group) and 1 uterine rupture (in the multiple-misoprostol group). There were no cases of thromboembolism, hysterectomy, or death [6]

Also, Lokugamage et al., found that, nausea, vomiting, and diarrhoea rates were similar in both groups, there were no cases of uterine rupture [7]

\section{Conclusion:}

Induction of labour is a common obstetric intervention and the use of misoprostol as an induction agent is important due to its low cost and stability at room temperature. These additional advantages make it a suitable agent, particularly in under-resourced settings and tropical countries. Moreover, the vaginal single-dose misoprostol appears to be an acceptable alternative to a multiple dose regimen for cervical ripening before the induction of labor. Our data indicates that there was no difference regarding the clinical efficacy between two labour induction regimens of vaginal misoprostol.

\section{References}

1- HOFMEYR G.J., GÜLMEZOGLU A.M. and PILEGGI C.: Vaginal misoprostol for cervical ripening and induction of labour. Cochrane Database of Systematic Reviews, 2010.

2- GÜLMEZOGLU A.M., CROWTHER C.A., MIDDLETON P., et al.: Induction of labour for improving birth outcomes for women at or beyond term. Cochrane Database of Systematic Reviews, 2012.

3- WING D.A. and SHEIBANI L.: Pharmacotherapy options for labor induction. Expert opinion on pharmacotherapy, 16: 1657-68, 2015.

4- MEYER M., PFLUM J. and HOWARD D.: Outpatient misoprostol compared with dinoprostone gel for preinduction cervical ripening: A randomized controlled trial. Obstetrics \& Gynecology, 105: 466-72, 2005.

5- ROUSE D.J., WEINER S.J., BLOOM S.L., et al.: Failed labor induction: Toward an objective diagnosis. Obstetrics and gynecology, 117: 267, 2011.

6- PIMENTEL V.M., ARABKHAZAELI M., MOON J.Y., et al.: Induction of labor using one dose vs multiple doses of misoprostol: A randomized controlled trial. American Journal of Obstetrics \& Gynecology, 218: 614.e611614.e618, 2018.

7- LOKUGAMAGE A., FORSYTH S., SULLIVAN K., et al.: Randomized trial in multiparous patients: Investigating 
a single vs. two-dose regimen of intravaginal misoprostol for induction of labor. Acta obstetricia et gynecologica Scandinavica, 82: 138-42, 2003.

8- WING D.A. and PAUL R.H.: A comparison of differing dosing regimens of vaginally administered misoprostol for preinduction cervical ripening and labor induction.
American Journal of Obstetrics and Gynecology, 175: 158-64, 1996.

9- GIRIJA S. and MANJUNATH A.P.: Comparison of two dosing regimens of vaginal misoprostol for labour induction: A randomised controlled trial. J. Turk. Ger. Gynecol. Assoc., 10: 220-5, 2009.

\title{
دراسة للمقارنة بين تحريض المخاض بواسطة جروعة واحدة

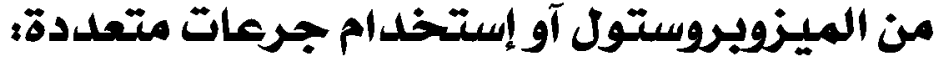 دراسة عشوائية خاضعة آلمراقية
}

\author{
يتحتم فى بعض الآحيان إنهاء الحمل لصالح الآم آى الجنين ويوجد إهتمام متزايد فى إستخدام الميزوبروبتهل كنظير إصطناعى

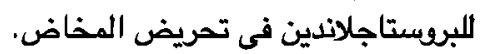

يعتبر تحريض المخاض تدخل شائع في علم الولادة والذى بلودة يجعل الميزوبروبتقل نو آهمية في هذا المجال حيث آنه غير مكلف ويخزن

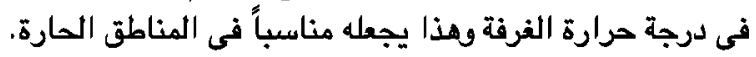

في هذه الدراسة كانت نقطة الإهتمام والهدف من البحث هو المقارنة بين معدل الولادة المهبلية خلال عب ساعة بين السيدات اللاتى خضعن لتحريض المخاض بين اللاتى تلقين جرعة واحدة من المينوبروبتول مع تلقي ه جرعات من هذا الدواء هواء.

\section{تم تعيين Y. Y سيدة بكرية في هذه الدراسة. تم تقسيمهن إلى مجموعتين كل مجموعة تتكنف من ب.1 سيدة.}

المجموعة الأولى تم إعطائها جرعة واحدة من الميزبيوبستول المهبلى والمجموعة الآخرى تم إعطاؤها آكثر من جرعة من نقس الدواء بلداء

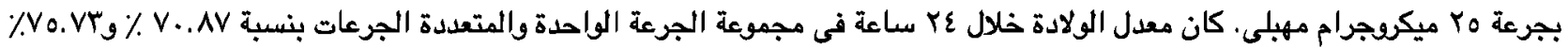

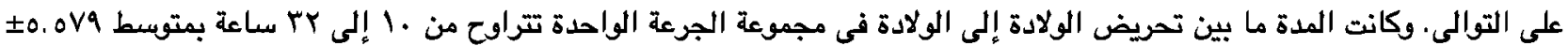

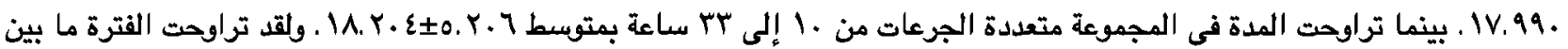

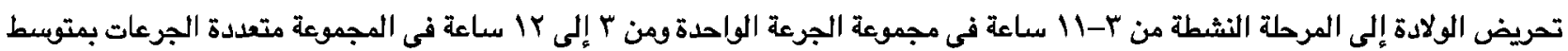

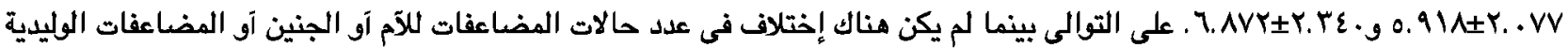

$$
\text { بين المجموعتين. }
$$

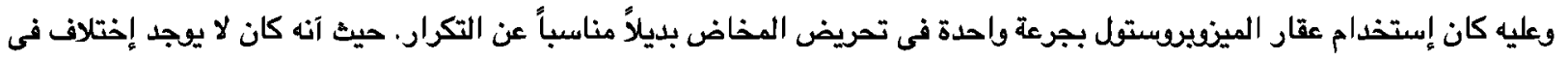

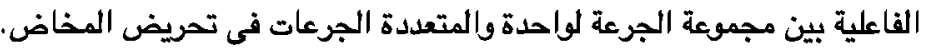

